\title{
Identification of Triacylglycerol Composition of Some Olive Oil Cultivars Cultivated in Some Different Areas in Egypt
}

\author{
Rania I.M. Almoselhy, Susan M.M. Abd-EImageed and M.E.I. Elsorady
}

Oils and Fats Research Department, Food Technology Research Institute, Agricultural Research Center, Giza, Egypt.

Received: 04 Sept. 2019 / Accepted 24 Oct. 2019 / Publication date: 05 Nov. 2019

\begin{abstract}
Three important Egyptian olive cultivars (Coratina, Kroneiki and Picual) were collected from different areas: (Horticulture Res. Inst. Giza, Qassaseen Ismaelia and Khatatba) in Egypt on the middle of November, 2016. Triacylglycerol (TAG) compositions were studied. As purity parameters, triacylglycerol composition in the oil samples was determined according to International Olive Council. All types of oils were characterized by three main TAG: OOO + PLP + PoPP, SOL + POO and OOL + LnPP and six secondary TAG: SLL+PLO, SOO, POP, OLL, OOLn + PoOL, and POS + SLS. Furthermore, small amounts $(<1.0 \%)$ of seven TAG: PLL + PoPoO, PoOP + SpoL + SOLn + SpoPo, OLLn + PoLL, LLL, PoOO, PLLn and POLn + PpoPO + PpoL were also identified in all analyzed samples. OOO was the major TAG found in all varieties from all areas, presented a range from 30.32 to $32.90 \%$. Followed by POO triacylglyceride, which presented a range from 26.45 to $28.36 \%$. Then OOL came in the following representing a range from 12.00 to $13.91 \%$. Results revealed that, there were significant differences among varieties in our study in terms of TAG contents. Moreover, these results are in accordance with those found in the fatty acid composition. At the same time significant differences were clearly found in POO, LLL TAG beside ECN42 values obtained by HPLC analysis.
\end{abstract}

Keywords: Triacylglycerol, Fatty acids, Extra virgin olive oil, Coratina, Kroneiki, Picual, ECN42, OOO, POO, OOL, LLL, GC, HPLC $\mathrm{O}=$ =leic, $\mathrm{P}=$ Palmitic, $\mathrm{S}=$ Stearic, Po=Palmitoleic, $\mathrm{L}=$ Linoleic, $\mathrm{Ln}=$ Linolenic

\section{Introduction}

Olive oil is one of the oldest known vegetable oils extracted from fruits of the olive tree, Olea europaea, L. by using only physical methods, which include crushing of olives, malaxation of resulting pastes and separation of the oily phase (Angerosa et al., 2001). Virgin olive oil composition influence by several factors like cultivar, environment, and agronomic practices affect the fruit physiology, and also processing and storage conditions affect the oil composition (Guerfel et al., 2012). Olive oil is composed of triacylglycerols (9798\%) and minor compounds (around $2 \%$ ) such as hydrocarbons, aliphatic alcohols, sterols, phenolic compounds, tocopherols (Koseoglu et al., 2016). The fatty acid composition and triacylglycerol content of virgin olive oil differs considerably depending mainly on latitude, climate, variety and maturity stage of olives (Sevim et al., 2013). Olive oils consist predominantly of TAG that generally follows a unique and typical pattern in the glycerol molecule being characteristics in the different oil seeds. TAG composition is immensely useful for the characterization and discrimination, as well authentication of olive oils or its geographical location (Galeano et al., 2005). Olive oil has a high resistance to oxidative deterioration due to its fatty acid composition, characterized by high monounsaturated-to polyunsaturated fatty acid ration, and to the presence of minor compounds. Despite its antioxidant affect, extra virgin olive oil undergoes oxidative process during storage, which influences its organoleptic properties and the nutritional value (Bilancia et al., 2007). No significant difference was determined for TAG composition of olive oils in terms of maturity index. This can be caused by close maturity index of olive oils (Koseoglu et al., 2017).

This study was aimed to characterize TAG composition of three important olive cultivars cultivated in Egypt; Coratina, Kroneiki and Picual and were collected from different geographical areas; Horticulture Research Institute in Giza, Qassaseen Ismaelia and Khatatba in Egypt, in the middle of

Corresponding Author: Rania I.M. Almoselhy, Oils and Fats Research Department, Food Technology Research Institute, Agricultural Research Center, Giza, Egypt.

E-mail: rania_almoselhy@outlook.com 
November, 2016. Since there is a shortage in research studies and data concerning determination of TAG in olive oil in Egypt.

\section{Materials and Methods}

\section{Materials}

Olive fruits of Coratina, Kroneiki and Picual varieties were harvested during mid November, 2016 from three different regions (Horticulture Research Institute in Giza, Qassaseen Ismaelia and Khatatba) in Egypt.

All solvents and chemicals used in all studies were obtained from Sigma Chemical Co. and were of analytical and HPLC grades.

\section{Oil Extraction}

The oil was immediately extracted by means of the continuous extraction system. The samples were then kept in dark glasses at $-18^{\circ} \mathrm{C}$, until their analyses.

\section{Analytical Methods}

\section{Refractive Index (RI)}

The refractive index of oils was determined according to the method described in AOAC (2000) using Carl Zeiss Refractometer, and the results were standardized at $20^{\circ} \mathrm{C}$.

\section{Acidity}

The acidity (as oleic acid \%) was determined according to the method outlined in AOAC (2000).

\section{Peroxide Value (PV)}

The peroxide value (mequivalent of $\mathrm{O} 2 / \mathrm{kg}$ oil) was determined according to the procedure described in AOAC (2000).

\section{Oxidative Stability}

The oxidative stability of oils was evaluated by the Rancimat method (Gutierrez, 1989). Stability was expressed as induction period (IP) per hours measured using Rancimat 679 apparatus (Metrohm, Switzerland).

\section{Fatty Acid Composition}

The fatty acid composition was converted into methyl ester according to ISO 12966-2:2011 (2011) and determined by GC.

\section{Triglycerides and ECN42 Determination}

Determination of triglycerides was carried out according to the method described in IOC, COI/T.20/Doc. No 25/Rev. 1 (2013a) by HPLC.

\section{Oil purification}

An SPE silica gel cartridge placed in a vacuum elution apparatus, washed under vacuum with $6 \mathrm{ml}$ of hexane. The vacuum is released to prevent column from drying and a conical flask is placed under cartridge. A solution of oil ( $0.12 \mathrm{~g}$, approximately) in $0.5 \mathrm{ml}$ of hexane is loaded into column, and solution is pulled through, then eluted with $10 \mathrm{ml}$ of solvent mixture of hexane-diethyl ether $(87: 13 \mathrm{v} / \mathrm{v})$ under vacuum. The eluted solvent is homogenized and approximately half of volume is poured into another conical flask. Both solutions are separately evaporated to dryness in a rotary evaporator under reduced pressure at room temperature. For triacylglycerol analysis, one of residues is dissolved in $1 \mathrm{ml}$ of acetone and poured into a 5-ml screw top glass tube. The other residue is dissolved in $1 \mathrm{ml}$ of Isooctane and poured into a second 5-ml screw top glass tube for preparing fatty acid methyl esters.

\section{Instrumentation}

Determination of triacylglycerol was carried out using Agilent 1200 HPLC Liquid 
Chromatography System equipped with auto-sampling injector.

Calculation of triacylglycerols composition from fatty acid composition and Determination of ECN42

Calculation of triacylglycerols from fatty acid composition of olive oil cultivars under investigation and the mathematical algorithms used for the detection of extraneous oils in olive oil by comparison with data base built from genuine olive oils were determined according to IOC, COI/T.20/Doc. No 25/Rev. 1 (2013a).

\section{Results and Discussion}

\section{Physical and Chemical Characteristics of Olive Oils}

Refractive index is an important physical characteristic of oils, it has relationship to structure. Refractive index plays an important role in characterizing oils. Refractive index values for the studied oils ranged between 1.4678-1.4696. These variations in refractive indices of the corresponding oils under investigation were attributed to their structure, chain length and the differences in fatty acid composition of these oils containing different profiles, especially linoleic acid (C18:2) content as shown later in Table (1). The obtained refractive indices of the studied oils agreed with Codex standard for olive oils (2013).

Acidity is a measure of the amount of free fatty acids present in oil due to both hydrolysis of its triglycerides and oxidation of double bonds of the unsaturated acyl chains which produced free fatty acids with low molecular weight. It has been frequently used as an important parameter to monitor the quality of oils and to show the case of hydrolysis and oxidation which are induced in the oil. Acidity showed a variation among varieties ranging between $0.13-0.19 \%$ (as oleic acid), and these values showed that all the produced oils are classified extra virgin according to IOC (2013b).

Peroxide value gives the initial evidence of rancidity in unsaturated fats and oils. It gives a measure of the extent to which an oil sample has undergone primary oxidation. Oils with a high degree of unsaturation are most susceptible to autoxidation. Peroxide values also showed difference between oils varieties with values ranged between 1.15-2.54 (meq O2 / $\mathrm{kg}$ oil). The obtained peroxide values of the studied oils agreed with Codex standard for olive oils (2013).

Oxidative stability is a very important parameter for evaluating the quality of oils once it gives a good perception and estimation of the susceptibility to oxidation process. Oxidative stability, in terms of measurement of induction periods (Rancimat, $20 \mathrm{~h} \mathrm{~h}^{-1}, 100^{\circ} \mathrm{C}$ ) of the tested oils ranged from 24.00 to 36.20 hours for different varieties. The oxidative stability of oils attributed to FA composition and minor component content in the oils (Table 1).

Table 1: Physical and Chemical Characteristics of Olive Oils

\begin{tabular}{lcccc}
\hline \multicolumn{1}{c}{ Oil Cultivars } & $\begin{array}{c}\text { Refractive index } \\
\mathbf{a t ~ 2 0}^{\circ} \mathbf{C}\end{array}$ & $\begin{array}{c}\text { Acidity } \\
\mathbf{\%}\end{array}$ & $\begin{array}{c}\text { Peroxide } \\
\text { Value }\end{array}$ & $\begin{array}{c}\text { Oxidative } \\
\text { Stability (h) }\end{array}$ \\
\hline Coratina Khatatba & 1.4685 & 0.13 & 1.50 & 34.20 \\
Kroneiki Khatatba & 1.4680 & 0.17 & 2.08 & 25.80 \\
Coratina Horticult Giza & 1.4690 & 0.16 & 1.15 & 36.20 \\
Kroneiki Horticult Giza & 1.4692 & 0.18 & 1.99 & 26.50 \\
Coratina Qassaseen Ismaelia & 1.4682 & 0.15 & 1.78 & 28.40 \\
Kroneiki Qassaseen Ismaelia & 1.4696 & 0.19 & 2.05 & 24.80 \\
Picual Qassaseen Ismaelia & 1.4678 & 0.19 & 2.54 & 24.00 \\
\hline
\end{tabular}

\section{Fatty Acid composition}

Fatty acids are the basic building blocks of oils. Analysis of fatty acids from oils is performed by gas-chromatography (GC).

The fatty acids composition of extra virgin olive oils of Coratina, Kroneiki and Picual varieties from different geographical areas (Giza - Qassaseen - Khatatba) in the crop season (2016) were determined using GC, the obtained results are presented in Table (2).

The major fatty acids are those C16 and C18 saturated fatty acids (SFA) mainly palmitic and stearic acids and C18 monounsaturated fatty acids (MUFA) or polyunsaturated fatty acids (PUFA) mostly oleic (C18:1), linoleic (C18:2) and linolenic (C18:3) acids. As expected in Table (2), all the 
studied olive oils had elevated amounts of total unsaturated fatty acids ranged between $80.38 \%$ in Coratina Khatatba oil to $82.79 \%$ for Kroneiki Khatatba oil. The most predominant unsaturated fatty acids were oleic and linoleic acids. Kroneiki Qassaseen Ismaelia oil had the highest content of monounsaturated fatty acids, its percentage was $74.06 \%$, whereas, Kroneiki Khatatba oil had the lowest value of $67.91 \%$.

Table 2: Fatty acid composition \% of the studied olive oils

\begin{tabular}{lccccccc}
\hline Fatty Acid & $\begin{array}{c}\text { Coratina } \\
\text { Khatatba }\end{array}$ & $\begin{array}{c}\text { Kroneiki } \\
\text { Khatatba }\end{array}$ & $\begin{array}{c}\text { Coratina } \\
\text { Horticult } \\
\text { Giza }\end{array}$ & $\begin{array}{c}\text { Kroneiki } \\
\text { Horticult } \\
\text { Giza }\end{array}$ & $\begin{array}{c}\text { Coratina } \\
\text { Qassaseen } \\
\text { Ismaelia }\end{array}$ & $\begin{array}{c}\text { Kroneiki } \\
\text { Qassaseen } \\
\text { Ismaelia }\end{array}$ & $\begin{array}{c}\text { Picual } \\
\text { Qassaseen } \\
\text { Ismaelia }\end{array}$ \\
\hline C 16:0 & 16.72 & 15.18 & 14.65 & 15.85 & 15.32 & 14.96 & 15.69 \\
C 16:1 & 1.14 & 1.75 & 0.83 & 1.70 & 0.57 & 0.91 & 2.07 \\
C 17:0 & 0.00 & 0.04 & 0.04 & 0.10 & 0.05 & 0.00 & 0.03 \\
C 17:1 & 0.06 & 0.08 & 0.07 & 0.11 & 0.08 & 0.00 & 0.06 \\
C 18:0 & 2.05 & 1.56 & 2.10 & 2.40 & 2.23 & 2.64 & 3.44 \\
C 18:1 & 69.67 & 65.81 & 70.01 & 71.69 & 67.42 & 73.15 & 71.06 \\
C 18:2 & 8.31 & 13.90 & 10.34 & 6.28 & 12.43 & 7.22 & 6.21 \\
C 18:3 & 0.90 & 0.98 & 0.79 & 0.59 & 0.90 & 0.63 & 0.80 \\
C 20:0 & 0.37 & 0.36 & 0.50 & 0.71 & 0.48 & 0.47 & 0.36 \\
C 20:1 & 0.30 & 0.27 & 0.47 & 0.07 & 0.43 & 0.00 & 0.21 \\
$\mathbf{\Sigma}$ SFA & 19.14 & 17.14 & 17.29 & 19.06 & 18.08 & 18.07 & 19.52 \\
$\mathbf{\Sigma}$ USFA & 80.38 & 82.79 & 82.51 & 80.44 & 81.83 & 81.91 & 80.41 \\
$\mathbf{\Sigma}$ MUFA & 71.17 & 67.91 & 71.38 & 73.57 & 68.50 & 74.06 & 73.40 \\
$\mathbf{\Sigma}$ PUFA & 9.21 & 14.88 & 11.13 & 6.87 & 13.33 & 7.85 & 7.01 \\
MUFA/SFA & 3.72 & 3.96 & 4.13 & 3.86 & 3.79 & 4.10 & 3.76 \\
MUFA/PUFA & 7.73 & 4.56 & 6.41 & 10.71 & 5.14 & 9.43 & 10.47 \\
C 16:0 / C 18:2 & 2.01 & 1.10 & 1.42 & 2.52 & 1.23 & 2.07 & 2.53 \\
C18:1/C18:2 & 8.38 & 4.73 & 6.77 & 11.42 & 5.42 & 10.13 & 11.44 \\
C18:2/C18:3 & 9.23 & 14.18 & 13.10 & 10.64 & 13.81 & 11.46 & 7.76 \\
\hline
\end{tabular}

It was noticed that the relative ratios of $\mathrm{C} 16: 0 / \mathrm{C} 18: 2$ and $\mathrm{C} 18: 1 / \mathrm{C} 18: 2$ were correlated with the relative ratio of $\Sigma$ MUFA / $\Sigma$ PUFA which were a helpful index for distinguishing oils under study. In addition, the ratio of $\mathrm{C} 18: 2 / \mathrm{C} 18: 3$ was also helpful to distinguish the oil.

It was observed from the results, that all oils characterized with their high contents of monounsaturated fatty acid oleic and low contents in the polyunsaturated linoleic acid, makes these oils more stable. Furthermore, all cultivars can be differentiated since the relative percentage of oleic and linoleic acids showed variations. The distribution of these fatty acids and the different relationships among them make up an oil acidic profile that can be used to identify all varieties, and determine the nutritional quality of oils. Some researchers demonstrated the importance of that relationship in the nutritional quality of the oil and its oxidative stability. It was found a linoleic/linolenic relationship. Note the importance of this relationship in nutrition because nowadays it is considered that a moderate contribution of linoleic acid is suitable to the current trends of a healthy diet where the intake of these essential fatty acids is important for preserving cardiovascular health. The data obtained confirm that the distribution of fatty acids is greatly influenced by olive variety (Fuentesa et al., 2015). The obtained data are in accordance with that reported by IOC, COI/T.15/NC No. 3/Rev. 7. (2013b).

\section{Triglyceride composition}

Triglycerides composition has established as a measurement of quality and authenticity of vegetable oils. TAG composition is influenced by different cultivars (Koseoglu et al., 2017).

It is known that the structure of glycerol backbone of TAG fraction influences the physicochemical, physiological, and nutritional properties of lipids. A deeper knowledge of these aspects can be useful to determine the geographical origin and varieties and to detect food fraud, and to predict nutritional value (Blasi et al., 2019).

The composition (\%) of triglycerides (TAG), and TAG fractions, expressed as equivalent carbon number $(\mathrm{ECN})$ in Coratina, Kroneiki and Picual olive oil varieties of different areas.

(Horticulture Res. Inst. Giza - Qassaseen Ismaelia - Khatatba) are shown in Table (3). 
Table 3: Triacylglycerol composition (\%) of the studied olive oils

\begin{tabular}{|c|c|c|c|c|c|c|c|}
\hline TAG & $\begin{array}{l}\text { Coratina } \\
\text { Khatatba }\end{array}$ & $\begin{array}{l}\text { Kroneiki } \\
\text { Khatatba }\end{array}$ & $\begin{array}{c}\text { Coratina } \\
\text { Horticult } \\
\text { Giza } \\
\end{array}$ & $\begin{array}{c}\text { Kroneiki } \\
\text { Horticult } \\
\text { Giza } \\
\end{array}$ & $\begin{array}{c}\text { Coratina } \\
\text { Qassaseen } \\
\text { Ismaelia } \\
\end{array}$ & $\begin{array}{c}\text { Kroneiki } \\
\text { Qassaseen } \\
\text { Ismaelia } \\
\end{array}$ & $\begin{array}{c}\text { Picual } \\
\text { Qassaseen } \\
\text { Ismaelia } \\
\end{array}$ \\
\hline \multicolumn{8}{|l|}{ ECN 42} \\
\hline LLL & 0.15 & 0.52 & 0.13 & 0.11 & 0.13 & 0.06 & 0.03 \\
\hline OLLn+PoLL & 0.44 & 0.40 & 0.44 & 0.30 & 0.45 & 0.35 & 0.39 \\
\hline PLLn & 0.10 & 0.35 & 0.19 & 0.09 & 0.10 & 0.10 & 0.19 \\
\hline \multicolumn{8}{|l|}{ ECN 44} \\
\hline OLL & 2.37 & 2.40 & 2.36 & 2.10 & 2.39 & 2.17 & 2.10 \\
\hline $\mathrm{OOLn}+\mathrm{PoOL}$ & 2.30 & 2.30 & 1.90 & 2.18 & 2.70 & 2.12 & 2.18 \\
\hline $\mathrm{PLL}+\mathrm{PoPoO}$ & 1.10 & 2.40 & 0.99 & 1.00 & 1.20 & 0.89 & 1.00 \\
\hline $\mathrm{POLn}+\mathrm{PpoPo}+$ & & & & & & & \\
\hline $\begin{array}{c}\text { PpoL } \\
\text { ECN } 46\end{array}$ & 0.20 & 1.05 & 0.19 & 0.17 & 0.18 & 0.08 & 0.17 \\
\hline $\mathrm{OOL}+\mathrm{LnPP}$ & 13.70 & 13.50 & 13.91 & 12.00 & 13.10 & 13.55 & 13.09 \\
\hline PoOO & 0.25 & 0.17 & 0.25 & 0.12 & 0.24 & 0.14 & 0.25 \\
\hline SLL+PLO & 8.70 & 8.84 & 8.74 & 8.33 & 8.50 & 8.51 & 8.32 \\
\hline $\begin{array}{c}\mathrm{PoOP}+\mathrm{SpoL}+ \\
\text { SOLn+SpoPo } \\
\text { ECN } 48\end{array}$ & 0.89 & 0.78 & 0.89 & 0.75 & 0.81 & 0.78 & 0.88 \\
\hline $\begin{array}{l}\text { OOO+PLP } \\
+ \text { PoPP }\end{array}$ & 32.34 & 30.32 & 32.21 & 32.43 & 32.90 & 32.80 & 32.70 \\
\hline $\begin{array}{c}\text { SOL+POO } \\
\text { ECN 50 }\end{array}$ & 26.76 & 27.95 & 26.45 & 28.36 & 26.93 & 28.16 & 28.28 \\
\hline POP & 4.59 & 2.64 & 4.57 & 4.27 & 4.51 & 4.24 & 4.65 \\
\hline SOO & 4.68 & 4.40 & 4.58 & 4.61 & 4.17 & 4.56 & 4.13 \\
\hline POS+SLS & 1.40 & 1.40 & 1.36 & 1.39 & 1.36 & 1.38 & 1.34 \\
\hline$\Delta \mathrm{ECN} 42$ & 0.16 & 0.13 & 0.16 & 0.19 & 0.13 & 0.19 & 0.20 \\
\hline
\end{tabular}

$\mathrm{ECN}$ is defined as the total carbon number in a triacylglycerol molecule

(ECN Carbon Number $-2 *$ Number of Double Bonds)

Palmitic; P $(\mathrm{C} 16: 0)=$ methyl ester + ethyl ester

Stearic; $\mathrm{S}(\mathrm{C} 18: 0)=$ methyl ester

Palmitoleic; Po $(\mathrm{C} 16: 1)=$ sum of methyl esters of the two cis-isomers

Oleic; $\mathrm{O}(\mathrm{C} 18: 1)=$ sum of methyl esters of the two cis-isomers + ethyl ester + trans-isomers

Linoleic; L (C18:2) = methyl ester+ ethyl ester + trans-isomers Linolenic; Ln (C18:3) = methyl ester + trans-isomers

All samples were characterized by three main TAG: OOO + PLP + PoPP, SOL +POO and OOL + LnPP and six TAG structured: SLL+PLO, SOO, POP, OLL, OOLn + PoOL, and POS+SLS. Furthermore, small amounts $(<1.0 \%)$ of seven TAG structured: PLL + PoPoO, PoOP + SpoL + SOLn + SpoPo, OLLn + PoLL, LLL, PoOO, PLLn and POLn + PpoPo + PpoL were also identified in all the analyzed samples. OOO was the major TAG found in all varieties in all geographical areas, presented a range from 30.32 to $32.90 \%$. POO was the second triacylglyceride on the basis of the main predominate TAG, which represented a range from 26.45 to $28.36 \%$.

At the same time, OOL was represented the following TAG range from 12.00 to $13.91 \%$. Therefore, we can see that there are differences among varieties in our study in terms of TAG contents. Moreover, these results are in accordance with those found in the fatty acid composition.

Another quality parameter, the $\triangle \mathrm{ECN} 42$ is also shown in Table (3). According to IOC, COI/T.20/Doc. No 25/Rev. 1 (2013a), the $\Delta \mathrm{ECN} 42$ maximum difference admitted is $<0.2$ for extra virgin oils. The difference between actual and theoretical $\triangle \mathrm{ECN} 42$ values used to discriminate genuine and adulterated olive oil to be distinguished (Eid et al., 2012). It is indeed a valid method to detect the presence of seed oil in olive oil. $\triangle \mathrm{ECN} 42$ has values in the range of those of olive oil in other varieties. The above results revealed that, the correlation between linolenic acid, trilinolein content and $\triangle \mathrm{ECN} 42$ has some shortcomings. To put it in other words, certain vegetable oils have high linolenic acid, low LLL content and high $\triangle \mathrm{ECN} 42$. Certain others exhibit low linolenic acid, high LLL content and low $\triangle \mathrm{ECN} 42$, whereas some others have high linolenic acid, low LLL content and low $\triangle \mathrm{ECN} 42$. 


\section{Conclusion}

It can concluded that triacylglycerol compositions, very useful data to characterize the chemical and nutritional properties of the TAG fraction, and it can be used to discriminate monovarietal extra virgin olive oil samples. The olive oil TAGs content of Egyptian olive cultivars (Coratina, Kroneiki and Picual) collected from different geographical areas (Horticulture Giza, Qassaseen Ismaelia and Khatatba) were determined. For all olive oil varieties: OOO ranging from 30.32 to $32.90 \%$, POO 26.45 to $28.36 \%$, OOL 12.00 to $13.91 \%$, the study had revealed difference in POO, LLL content and ECN42 (HPLC value) of olive oil. The data showed that LLL, POO, ECN 42 (HPLC value), PLL/OLL and $\mathrm{OOO} / \mathrm{POO}$ content of olive oil played an important role in the characterization and identification of olive oil cultivars from different geographical areas in Egypt.

\section{References}

Angerosa F., R. Mostallino, C. Basti and R. Vito, 2001. "Influence of malaxation temperature and time on the quality of virgin olive oils." Food Chemistry, 72:19-28.

AOAC, 2000. Official Methods of Analysis, Vol. II, $16^{\text {th }}$ Edition, Virginia 22201, Arlington.

Bilancia, M.T., F. Caponio, E. Sikorska, A. Pasqualone and C. Summo, 2007. "Correlation of triacylglycerol oligopolymers and oxidized triacylglycerols to quality parameters in extra virgin olive oil during storage". Food Research International, 40:855- 861.

Blasi, F., L. Pollini and L. Cossignani, 2019. Varietal Authentication of Extra Virgin Olive Oils by Triacylglycerols and Volatiles Analysis. Foods, 8, 58.

Codex standard for olive oils and olive pomace oils , 2013. CODEX STAN 33-1981.

Eid, M.M., M.E.I. ELSORADY and S. E. Ali, 2012. "Traceability of olive oil authentication using DNA molecular evaluation, thermal analysis", J. Biol. Chem. Environ. Sci., 2012, vol. 7 (4): 259-284.

Fuentesa, M., C. De Miguel, A. Ranalli, M.N. Franco, M. Martinez and D. Martin-Vertedor, 2015. "Chemical composition and sensory evaluation of virgin olive oils from "Morisca" and "Carrasquena" olive varieties", Grasas Aceites 66 (1), January-March 2015.

Galeano Diaz T., T. Duran Meras, J. Sanchez Casas and M.F. Alexandre Franco, 2005. "Characterization of virgin olive oils according to its triglycerides and sterols composition by chemometric methods", Food Control, 16: 339-347.

Guerfel M., M. Ben Masour, Y. Ouni, F. Guido and D. Boujnah, M. Zarrouk, 2012. "Triacylglycerols composition and volatile compounds of virgin olive oil from Chemlali cultivar: comparison among different planting densities". The Scientific World Journal, doi:10.1100/2012/354019.

Gutierrez, F., 1989. "Determinacion de la estabilidad oxidative de aceites de oliva vfrgenes: comparacidn entre el metodo del oxfgeno active (AOM) y el metodo Rancimat". Grasas y Aceites, 40:1-5.

IOC., 2013a. Global method for the detection of extraneous oils in olive oils. COI/T.20/Doc. No 25/Rev. 1. 2013.

IOC., 2013b. Trade standard applying to olive oils and olive-pomace oils. COI/T.15/NC No. 3/Rev. 7. 2013.

ISO 12966-2:2011, 2011. Animal and vegetable fats and oils - Gas chromatography of fatty acid methyl esters - Part 2: Preparation of methyl esters of fatty acids.

Koseoglu, O., D. Sevim and D. Ozdemir, 2017. "Determination of triacylglycerol composition of Ayvalik and Memecik olive oils during storage by chemometric methods". Sakarya Universitesi Fen Bilimleri Enstitusu Dergisi, 21 (6): 1497-1504.

Koseoglu, O., D. Sevim and P. Kadiroglu, 2016. "Quality characteristics and antioxidant properties of turkish monovarietal olive oils regarding stages of olive ripening", Food Chemistry, 212: 628-634.

Sevim D., O. Koseoglu and F. Ozturk Gungor, 2013. "Effect of different growing area on triacylglycerol composition of cv. Gemlik olive oil of Turkey", J Agri Faculty of Uludag University, 27(1): 4954 . 